An Overview of the Development, Testing, and Application of Composite Absorbers

Ferdinand Šebesta*

Jan John* 


\section{DISCLAIMER}

This report was prepared as an account of work sponsored by an agency of the United States Government. Neither the United States Government nor any agency thereof, nor any of their employees, make any warranty, express or implied, or assumes any legal liability or responsibility for the accuracy, completeness, or usefulness of any information, apparatus, product, or process disclosed, or represents that its use would not infringe privately owned rights. Reference herein to any specific commercial product, process, or service by trade name, trademark, manufacturer, or otherwise does not necessarily constitute or imply its endorsement, recommendation, or favoring by the United States Government or any agency thereof. The views and opinions of authors expressed herein do not necessarily state or reflect those of the United States Government or any agency thereof. 


\section{DISCLAIMER}

Portions of this document may be illegible in electronic image products. Images are produced from the best available original document. 


\section{CONTENTS}

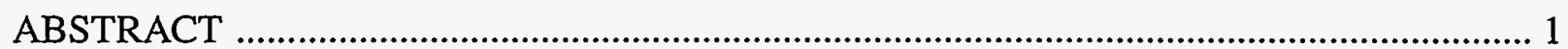

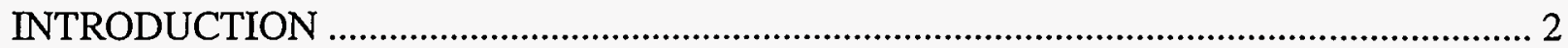

II. METHODS OF MODIFYING INORGANIC ION EXCHANGERS

FOR USE IN PACKED-BED COLUMNS ............................................................ 3

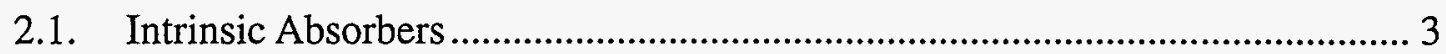

2.1.1. Natural Inorganic Ion Exchangers ................................................ 3

2.1.2. Synthetic Inorganic Ion Exchangers ............................................. 4

2.2. Supported Absorbers ................................................................................ 7

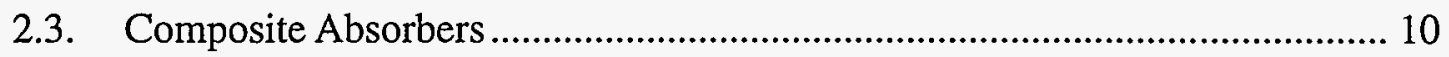

2.3.1. Composite Absorbers with an Inorganic Binding Matrix .................. 10

2.3.2. Composite Absorbers with an Organic Binding Matrix .................... 11

III. COMPOSITE ABSORBERS PROVIDED FOR EVALUATION AT LANL ................ 18

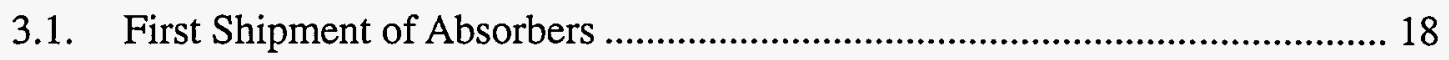

3.2. Second Shipment of Absorbers ............................................................. 19

IV. APPLICATIONS OF COMPOSITE ABSORBERS ................................................. 22

4.1 LANL Absorber Studies for Hanford High-Level Waste ........................... 22

4.2 Other Applications of PAN-Composite Absorbers ..................................... 22

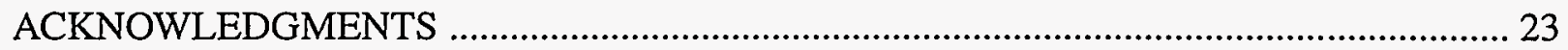

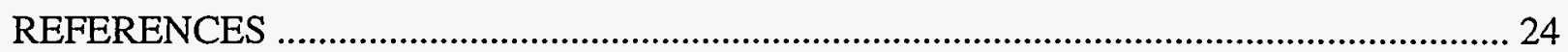




\title{
AN OVERVIEW OF THE DEVELOPMENT, TESTING, AND APPLICATION OF COMPOSITE ABSORBERS
}

by

\author{
Ferdinand Šebesta and Jan John
}

\begin{abstract}
Although inorganic exchangers offer many advantages for removing selected elements from radioactive waste streams, few of these materials are suitable for use in packed-bed columns. We review various adaptations of inorganic exchangers for use in columns, which include granular forms of the intrinsic absorbers, absorber compounds supported on other materials, and composite absorbers that use organic or inorganic binders. An organic binding polymer of polyacrylonitrile (PAN), developed at the Czech Technical University, has been demonstrated to offer advantages. We describe general methods for preparing inorganic exchange materials, which then are incorporated into PAN-based composites. Such PAN composites have been used to remove selected radionuclides from a variety of liquid waste streams. Sixteen different PAN composites were prepared for testing at Los Alamos National Laboratory (LANL) as part of an evaluation of potential partitioning agents for remediating the liquid waste in underground storage tanks at the Hanford site near Richland, Washington. Our collaboration with LANL is expected to continue for another 2 years.
\end{abstract}




\section{INTRODUCTION}

Composite ion exchangers (absorbers) have been developed and tested at the Department of Nuclear Chemistry, Czech Technical University (CTU), Prague, for several years. ${ }^{1-3}$ A general method for the preparation of composite organic-inorganic absorbers developed at CTU ${ }^{4,5}$ uses polyacrylonitrile (PAN) as a binding polymer. Various powdered active components, such as synthetic inorganic ion exchangers, can be embedded into this matrix.

The main area of potential application of these composite absorbers is the treatment of liquid radioactive wastes from different sources. The results of testing some of our developed composite absorbers for treating several radioactive wastes were summarized at the 1993 International Conference on Nuclear Waste Management and Environmental Remediation. ${ }^{6}$ Some of these developed composite absorbers are being used to treat liquid radioactive wastes from the decommissioning of the A-1 nuclear power plant (Slovak Republic). ${ }^{7,8}$ We assume that the numerous advantages of composite absorbers could be applied in many other areas, such as treating various types of waste and underground waters contaminated by heavy and toxic metals.

Los Alamos National Laboratory (LANL) is pursuing related development projects for decreasing the level of hazardous components in nuclear waste streams at LANL and other U.S. Department of Energy facilities. To coordinate efforts between these institutions and to provide financial support for research and development of composite absorbers at CTU, a workscope and schedule have been agreed to in a "Memorandum of Understanding between Los Alamos National Laboratory and Czech Technical University." The terms of this memorandum include the preparation of a baseline report, quarterly, and annual reports, summaries of recent research done at CTU, and projected activities. This report is a revised and updated version of the initial baseline report produced for LANL as part of the cited collaboration. 


\section{METHODS OF MODIFYING INORGANIC ION EXCHANGERS FOR USE IN PACKED-BED COLUMNS}

The application of inorganic ion exchangers for treating liquid radioactive wastes has recently gained support. These exchangers are attractive for developing advanced new technologies that should ensure greater safety and lower cost. ${ }^{9}$ Areas of possible application of inorganic ion exchangers were recently evaluated by Hooper et al., ${ }^{10}$ who also specified the exact requirements that prospective absorbers should fulfill.

Inorganic ion exchangers have many advantages over synthetic organic ion exchangers. The main advantage of inorganic exchangers is their high selectivity for sorbing certain ions. Other advantages include greater thermal and radiation stabilities, generally good chemical stability even in strongly acid media, and compatibility with many of the matrices used for immobilization. The most serious disadvantage of synthetic inorganic ion exchangers is their unsuitable granular and mechanical properties that limit their use in column applications.

Many different methods have been proposed for preparing granules of inorganic ion exchangers and for improving the mechanical strength of these materials. On the basis of the preparation method used, the resulting ion exchangers can be classified in three groups. Intrinsic inorganic ion exchangers represent a group of ion exchangers prepared without any additives. Supported ion exchangers represent a group of inorganic ion exchangers, in which the active inorganic component is deposited on a suitable supporting material. Composite ion exchangers represent the group of inorganic ion exchangers modified by using a binding material to prepare larger particles with high granular strength.

Evaluating the suitability of these three groups of synthetic inorganic ion exchangers for treating liquid radioactive wastes is somewhat difficult. Each of the groups of granular inorganic ion exchangers exhibits certain advantages, as well as disadvantages.

In the following sections, we provide examples of various ways for preparing granular absorbers from single (as defined above) groups. Their properties are compared, and some possibilities for their application are evaluated. Although this survey is not complete, its primary aim is to summarize and provide examples of published methods for modifying inorganic ion exchangers for use in packed-bed columns.

\subsection{Intrinsic Absorbers}

2.1.1. Natural Inorganic Ion Exchangers. Natural inorganic ion exchangers are usually modified for use in packed-bed columns by crushing, followed by sieving to obtain particles of the required size. Finally, the fine particles are washed out by flushing the absorber with water. Examples of natural zeolites that are often used for treating liquid radioactive wastes are 
clinoptilolite, mordenite, and chabazite. The main advantage of natural inorganic ion exchangers is their low price; the main disadvantages are their poorly defined structures, low capacities, and impure chemical composition.

2.1.2. Synthetic Inorganic Ion Exchangers. Synthetic inorganic ion exchangers are insoluble inorganic compounds prepared by precipitation, usually in water solutions. Depending on the specific absorber prepared (type of chemical compound and method of preparation), the structure may be crystalline or amorphous. Most useful of such absorbers are those that can be prepared as crystalline particles sufficiently large to be directly used as the column bed material.

Unfortunately, few inorganic ion exchangers can be prepared in such suitable crystalline form. ${ }^{11,12}$ In most cases, the precipitated inorganic ion exchanger must be separated by filtration and the undesirable chemical admixtures washed out. Suitable granules of ion exchanger are then obtained by sieving the dried, crushed filtration cake to obtain the fraction with the required grain size. The finest particles are removed (that is, by decanting) before the granules are used. Vesely and Pekárek ${ }^{11,12}$ state that many granular inorganic ion exchangers can be prepared using this procedure.

An overview of the preparation of granular metal hexacyanoferrates by this procedure was published by Jacobi. ${ }^{13}$ Many inorganic ion exchangers commercially supplied by STMI-RAN (France) ${ }^{14}$ appear to be prepared in this way. The most commonly used absorber prepared by this procedure is cobalt potassium hexacyanoferrate (KCFC), proposed by Prout et al. ${ }^{15}$ Currently, $\mathrm{KCFC}$ is used in the large-scale treatment of liquid radioactive wastes in the Loviisa Nuclear Power Plant (NPP) in Finland. ${ }^{16}$

A technical disadvantage of the above procedure includes substantial losses of material as dust and particles smaller than the required grain size. Moreover, granules produced by this method sometime undergo decomposition during contact with the treated solution (that is, peptization). This phenomenon may cause increased resistance of the column bed, resulting in a decreased flow rate or even column plugging. Drying the filtration cake at an elevated temperature (a usual step of the procedure) significantly worsens the ion-exchange kinetics and sorption capacity of the resulting absorber.

In the case of microcrystalline precipitates, it is impossible to produce absorbers with sufficient mechanical strength using the described procedure. For this reason, additional special methods were developed to modify inorganic ion exchangers.

2.1.2.1. Slow-growth method. Under normal circumstances, ammonium salts of heteropolyacids may be prepared only in the form of very small crystals ( 200 mesh). A procedure for preparing larger particles $(0.4 \mathrm{~mm})$, described by Smit, ${ }^{17}$ consists of adding a concentrated solution of ammonium nitrate to crystals of molybdophosphoric acid. The resulting relatively strong agglomerates of ammonium salt had sufficient mechanical strength to withstand several sorption-desorption cycles. 
In a similar method used by Berák ${ }^{18}$ to prepare granules of barium sulfate activated by calcium, crushed calcium sulfate (as the natural mineral anhydrite or gypsum) was loaded in a chromatography column, and a solution of a barium salt was added.

The slow-growth method has also been used to prepare zinc or nickel hexacyanoferrates. ${ }^{19,20}$ In this method, local growth occurs on sodium or potassium ferrocyanide crystals placed in concentrated zinc or nickel solution to produce hollow spheres that lack the mechanical stability of solid particles. Particles of 0.1 to $0.5 \mathrm{~mm}$ can easily be prepared. The mechanical stability of a column filled with zinc potassium ferrocyanide was sufficient for processing a solution of 20,000 bed volumes. The chemical stability was verified for zinc ferrocyanide in solutions from $\mathrm{pH} 1$ to 10 and for nickel ferrocyanide from $\mathrm{pH} 0$ to 12 . The limiting factor in using hexacyanoferrate salts prepared in this way is a partial release of zinc or nickel cations from the absorber.

2.1.2.2. High-temperature treatment. An intrinsic absorber containing barium sulfate, activated by calcium, was prepared by heating a mixture of barium and calcium sulfates at $1000^{\circ} \mathrm{C}$ to $1300^{\circ} \mathrm{C}$. After cooling the molten mixture, the solid product was crushed and processed in the usual way to obtain granular material.21,22 A similar method was used to prepare potassium titanate fibers from a molten mixture of potassium carbonate and titanium oxide. ${ }^{23}$ Hydrothermal treatment for 20 hours at $200^{\circ} \mathrm{C}$ to $300^{\circ} \mathrm{C}$ was used to increase the crystallinity of sodium titanate..$^{24}$

2.1.2.3. Freeze-thaw method. This procedure was introduced to produce granules from inorganic ion exchangers that yield amorphous precipitates that settle and filter poorly. The method makes use of the fact that water is irreversibly separated when a gel (precipitate) is frozen, and the absorber becomes granular. After thawing, the granular absorber is separated from the solution and air-dried at ambient or elevated temperature. This method has been used to prepare various granular hydrated oxides- $\mathrm{SnO}_{2}, \mathrm{SiO}_{2}, \mathrm{MnO}_{2}, \mathrm{TiO}_{2}, \mathrm{ZrO}_{2}, \mathrm{Fe}_{2} \mathrm{O}_{3}$, and mixed absorbers-nickel hexacyanoferrate $+\mathrm{Ni}(\mathrm{OH})_{2}, \mathrm{PbS}+\mathrm{Pb}(\mathrm{OH})_{2}, \mathrm{NiS}+\mathrm{Ni}(\mathrm{OH})_{2} .{ }^{25}$

This method also has been used to prepare granular zirconyl phosphate ${ }^{26,27}$ and various hexacyanoferrates. ${ }^{28,13} \mathrm{Jacobi}^{13}$ performed a very detailed study of the possibilities for preparing sodium nickel hexacyanoferrate and concluded that the conditions under which the precipitates are frozen are crucial to obtaining a product with good granular form. This absorber has good sorption properties for cesium but is only completely stable in the range of $\mathrm{pH} 4$ to 10 . Below $\mathrm{pH} \sim 4$, nickel is released from the material into solution, but it decomposes above $\mathrm{pH} \sim 10$.

2.1.2.4. Sol-gel method. The use of the sol-gel technique to prepare spherical particles of inorganic ion exchangers was a significant contribution to developing procedures for modifying their granular and mechanical properties. This method converts a sol (or even a true solution), dispersed in an organic solvent, to a hydroxidic gel.29-31 Using this method, it is possible to prepare uniform spheres of hydroxidic gels from only polyvalent hydrolyzable cations, e.g., $\mathrm{Al}^{1+}, \mathrm{Fe}^{3+}, \mathrm{Cr}^{3+}, \mathrm{Si}^{4+}$, $\mathrm{Ti}^{4+}, \mathrm{Zr}^{4+}$, or their mixtures. 
A sol may be converted into a gel by either internal or external gelation. ${ }^{29,31}$ Internal gelation is generally used to prepare intrinsic absorbers. Sols may be dispersed in media that are immiscible with water (paraffin or silicon oils, kerosene, etc.) in chemical reactors equipped with good stirring capability, or in continuous gelation columns by introducing small droplets from capillaries. ${ }^{31}$

To extend the range of inorganic ion exchangers that can be prepared with the sol-gel method, a procedure for converting prepared hydroxidic gels was proposed and developed. ${ }^{29,30}$ The chemical flowchart for converting gel spheres (Fig. 1) substantially increases the types and combinations of inorganic ion exchangers that can be prepared with the sol-gel method. ${ }^{30}$

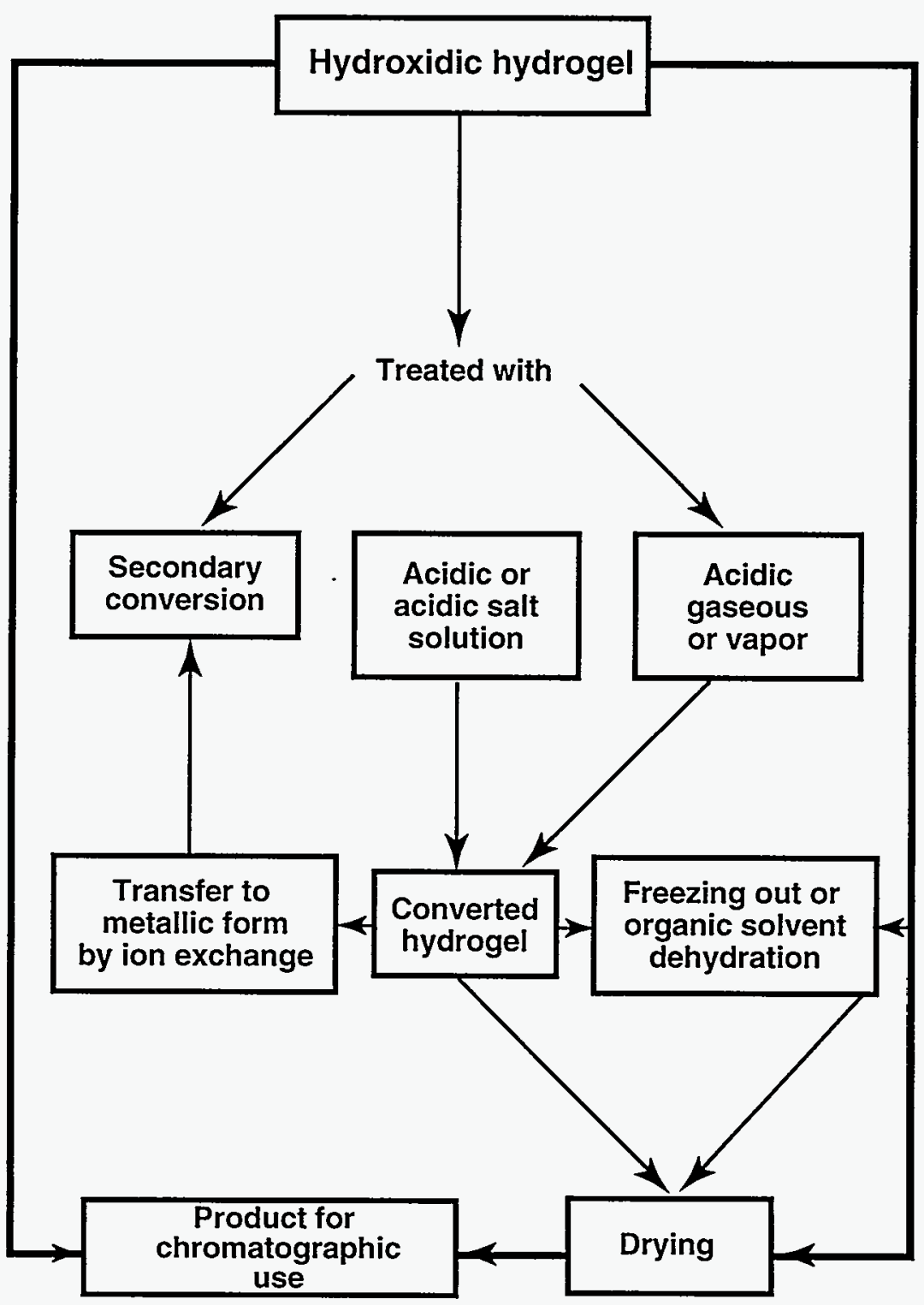

Fig. 1. Some options for preparing inorganic ion exchangers using the sol-gel method. 
Figure 2 presents a flowchart for preparing titanium phosphate gel. Among the disadvantages of the sol-gel method are the greater shrinkage of dried particles to hydrogels and the resulting products of their conversion to xerogels. Moreover, the procedure is not universal; for example, it is not possible to prepare zinc or nickel hexacyanoferrates using this method. ${ }^{20}$

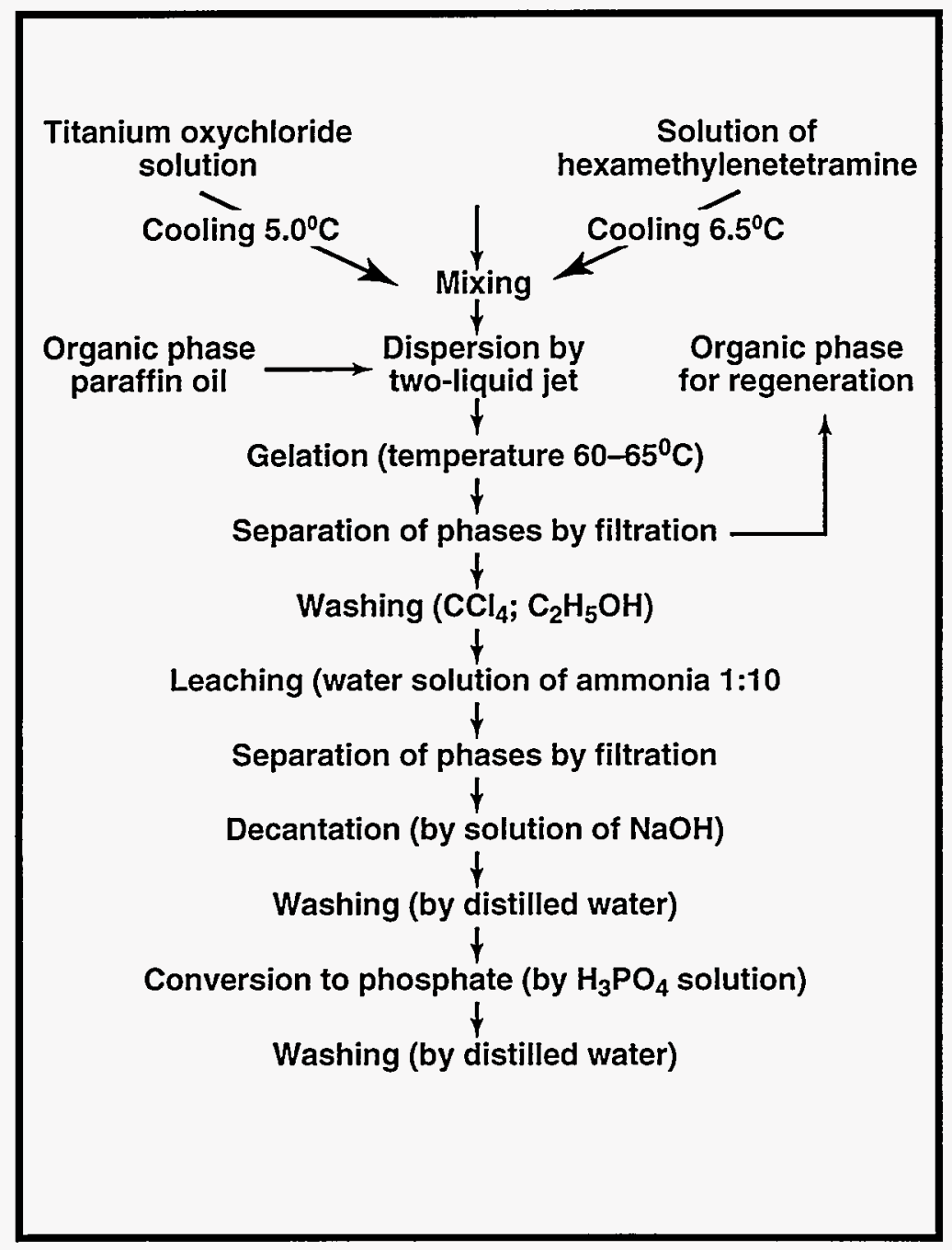

Fig. 2. Preparation of titanium phosphate using the sol-gel method.

\subsection{Supported Absorbers}

Many materials have been proposed as suitable supports for inorganic ion exchangers. Inert behavior is an essential requirement for these materials; that is, no ion exchange or sorption should take place on the support materials. The simplest way to prepare supported absorbers is to either mix the fine-grained, or amorphous, precipitate of the ion exchanger with an inert support material or induce it to precipitate on a suitable support. Materials used as supports include asbestos, charcoal, alumina, filtration paper, glass fibers, glass wadding, and other porous materials. ${ }^{11,12}$ 
Disadvantages of these procedures were a considerable increase in volume and problems with preparing materials for larger columns. The sorption capacity of the resulting columns was too low, and the ion exchanger washed out of the bed of the columns when they were used for longer periods.

Later, silica gel was proposed and used as a more suitable support for inorganic ion exchangers. In this case, inorganic ion exchangers were deposited on silica gel of a suitable grain size. Caletka et al. ${ }^{32-35}$ used silica gel as the support for various inorganic ion exchangers. They proposed procedures for depositing several hexacyanoferrates on different types of silica gel. ${ }^{32}$ Their intent was to develop the best procedure for producing absorbers with the highest sorption capacity. In addition, they studied the ion-exchange properties of phosphoantimonic acid prepared by various procedures and deposited on silica gel. ${ }^{33}$ This absorber was proposed for separating alkaline metals and strontium from acid solutions containing nitric acid. Using a similar technique, polyantimonic acid has been deposited on silica gel. ${ }^{34}$

Two different procedures were proposed for depositing ammonium molybdophosphate (AMP) on silica gel. This absorber was tested for separating radiocesium from acid solutions. ${ }^{35}$ Terada et al. ${ }^{36}$ used silica gel as the support AMP and some binary hexacyanoferrates used to concentrate radiocesium from natural waters. In a similar way, Ganzerli et al. ${ }^{37}$ used copper hexacyanoferrate deposited on silica gel to concentrate stable cesium from river and sea water.

In spite of this frequent use of silica gel as a support for inorganic ion exchangers, it has not been used on a broader scale to treat liquid radioactive wastes. Only the procedure for decontaminating waste solutions from ${ }^{137} \mathrm{Cs}$ proposed by Wilding ${ }^{38}$ was based on the use of AMP precipitated in situ on silica gel. This product contained $23 \%(\mathrm{w} / \mathrm{w})$ of AMP, and its sorption capacity was lower than that of a mixture of AMP with asbestos.

Porous stainless-steel membrane was used as a support for hydrous titanium and zirconium oxides. ${ }^{39}$ Titanium dioxide and zirconium dioxide were precipitated within the porous metal matrix using tetraisopropyl orthotitanate or zirconium propoxide and $\mathrm{LiOH}$ solution. Such stainlesssteel membranes may be impregnated with $\mathrm{TiO}_{2}$ equal to $7 \%$ of their weight. Impregnated steel membranes were tested as a means of removing radio-nuclides from the primary coolant used in pressurized water reactors.

Organic polymers shaped as beads have often been proposed as a support for inorganic ion exchangers. ${ }^{40-47}$ Watari et al. ${ }^{40}$ was the first to describe the preparation of copper hexacyanoferrateloaded anion exchange resin. Macroreticular anion exchange resin (Amberlite IRA-904) was converted to the hexacyanoferrate form, and the different hexacyanoferrates were precipitated with solutions of the respective metals (copper, iron, nickel). ${ }^{40,41}$ Lehto et al. ${ }^{42}$ also studied possible applications of IRA-400 and IRA-904 anion exchange resins and Chelex-100 chelating resin as supports for potassium cobalt hexacyanoferrates. However, Lehto selected granular potassium cobalt hexacyanoferrate for separating ${ }^{137} \mathrm{Cs}$ from concentrates at the Loviisa NPP. Amberlite 8 
IRA-900 macroreticular anion-exchange resin has been used to prepare AMP-bearing resin that retains 1.09 g AMP per gram IRA-900.43

Macroreticular anion exchange resin AG-MP-1 (Bio-Rad) and Dowex MSA-1, type MP, were used by Dosch $^{44}$ to prepare resins loaded with sodium titanate, sodium niobate, and sodium tantalate. His studies with sodium titanate-loaded resin, containing $30 \%$ to $40 \%(\mathrm{w} / \mathrm{w})$ of sodium titanate in the dry residue, proved that the sorption properties of sodium titanate are not influenced by the supporting material. Resin loaded with sodium titanate exhibited good mechanical stability, and a column filled with this resin was operated continuously for 527 hours with no evidence of particle attrition or channeling. The loaded resin also was shown to be stable to $5 \times 10^{6} \mathrm{~Gy}$ of radiation. Elution of spent resin and the possibility of its reuse were verified.

Other organic polymer beads were also employed as carriers for inorganic ion exchangers. Dry beads were first soaked in an aqueous solution containing one component of the ion exchanger. After removing the supernatant, an aqueous solution of the second component was added to precipitate the inorganic ion exchanger within the pores of the beads. Such a procedure was used to prepare a divinylbenzene-styrene copolymer loaded with $\mathrm{AMP}, 45$ which was used to determine cesium in sea water. Macroreticular spherical cellulose was also proposed as a support for inorganic ion exchangers. ${ }^{46}$ Cellulose loaded with nickel hexacyanoferrate ${ }^{47}$ was tested as a means for separating ${ }^{137} \mathrm{Cs}$ from liquid radioactive wastes in NPP A-1 (Slovak Republic).

Fibrous polymers as a support for inorganic ion exchangers were first used by Krishnaswami et al., ${ }^{48}$ who developed a procedure for impregnating acrylic fibers with iron hydroxide. Iron-treated fibers were used for the in situ extraction of various elements from sea water. Moore and Reid ${ }^{49}$ developed a procedure for impregnating acrylic fibers (Monsanto Acrilan, 3.0 denier, type B-16) with manganese oxides $\left(\mathrm{MnO}+\mathrm{MnO}_{2}\right)$. Their procedure included the conversion of the fiber to a cation-exchange resin by treatment with $6 \mathrm{M} \mathrm{NaOH}$ at $80^{\circ} \mathrm{C}$ to $90^{\circ} \mathrm{C}$, and the sorption of manganese from $5 \mathrm{M} \mathrm{MnCl}_{2}$ at $30^{\circ}$ to $40^{\circ} \mathrm{C}$ and a pH of $\sim 1$ to 2). The manganese-soaked fiber was immersed in $6 \mathrm{M} \mathrm{NaOH}$ at $25^{\circ} \mathrm{C}$ to precipitate $\mathrm{Mn}(\mathrm{OH})_{2}$, then separated, fluffed, and exposed to air to oxidize $\mathrm{Mn}(\mathrm{OH})_{2}$ to a mixture of hydrated $\mathrm{MnO}$ and $\mathrm{MnO}_{2}$. As much as 12 to $15 \mathrm{~g}$ of manganese was loaded per $100 \mathrm{~g}$ of fibers, and subsequent washing removed less than $50 \%$ of the loaded manganese from the fibers. These alkaline manganese-impregnated fibers have been used to remove radium and other trace metals from natural waters ${ }^{49}$ and radium from drinking water. 50

Later, a simpler procedure was developed for preparing manganese-impregnated fibers. ${ }^{51}$ Acrylic fibers were immersed in $0.5 \mathrm{M}$ potassium permanganate solution (at $70^{\circ} \mathrm{C}$ to $80^{\circ} \mathrm{C}$ ), which partially oxidized the fibers and deposited $\mathrm{MnO}_{2}$ on them. As much as $10 \mathrm{~g}$ of manganese could be loaded on $100 \mathrm{~g}$ of fibers. Loss of $\mathrm{MnO}_{2}$ from these manganese fibers during their use was less than $3 \%$. These manganese fibers are suitable for extracting lead, mercury, copper, zinc, cobalt, and cadmium from dilute solutions. 
Higuchi et al. ${ }^{52}$ patented a procedure for preparing $\mathrm{MnO}_{2}$, hexacyanoferrates, or their mixtures, supported on acrylic fiber in the form of woven or nonwoven cloth. These materials may be used to collect and concentrate radionuclides and heavy metals present in liquid radioactive wastes, industrial waste waters, and natural water. Acrylic fiber prepared by copolymerizing vinyl chloride with $8 \%(\mathrm{w} / \mathrm{w})$ methyl acrylate will withstand up to $30 \%$ hydrochloric acid, nitric acid, or sulfuric acid. However, the resistance of these fibers to alkaline solution is very low. The most suitable range of

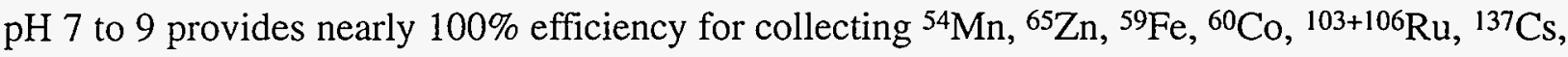
and ${ }^{144} \mathrm{Ce}$. The authors reported neither the quantities of inorganic ion exchangers that can be supported by acrylic fibers nor the sorption capacities of their materials.

\subsection{Composite Absorbers}

Powdered and microcrystalline inorganic ion exchangers may also be converted to granular form by using suitable binding materials. The required properties of such binding materials are the following: sufficient aggregation force, ample chemical stability, no adverse influence on the ionexchange properties of the inorganic exchanger, no ion-exchange properties of their own, high permeability for aqueous solutions of the targeted ions, and an ability to produce granules with a very high quantity of the active absorber component. Both inorganic and organic materials may be used as binding materials to prepare such composite absorbers.

2.3.1. Composite Absorbers with an Inorganic Binding Matrix. The higher radiation and thermal stability of inorganic binding materials makes them attractive for preparing composite absorbers to be used to treat liquid radioactive wastes. Possible inorganic binding materials include appropriate clay minerals, which may be mixed with powdered inorganic ion exchanger and water to form a paste of suitable consistency. This paste is then used to form pellets, which are dried and calcined to improve their mechanical strength. Similar procedures are used by many commercial firms to produce molecular sieves. However, calcination at elevated temperatures may deteriorate the sorption capacity and ion-exchange kinetics of the material.

Cement also has been used as a binding material for granulating nickel hexacyanoferrate..$^{53}$ First a dry mixture of cement and the hexacyanoferrate salt (3:2 or 4:1) was prepared and then mixed with water. The resulting dense grout was molded into the desired form. After 3 to 7 days of curing, the product was crushed and sieved. Granules obtained from both of these mixtures exhibited ample long-term stability in contact with solutions. The $\mathrm{K}_{\mathrm{D}}$ values for cesium from saline solutions ( $\sim 20 \%$ solutions of sodium and potassium salts) ranged from 4,000 to 8,000 .

An interesting procedure for granulating some inorganic ion exchangers was proposed by Peeters et al. ${ }^{54}$ Barium sulfate and barium carbonate are usually obtained as fine powders, and as such are unsuitable for use in industrial columns. However, a suitable structure can be imparted by 
preparing $\mathrm{BaSO}_{4}$ or $\mathrm{BaCO}_{3}$ as a mixed precipitate with nickel hexacyanoferrate. This mixed precipitate is filtered (without washing), dried, and ground into granules of the required size.

Another suitable binding material is silica gel. A sol-gel procedure is used for granulating powdered inorganic ion exchangers into a matrix of $\mathrm{SiO}_{2} .55$ Urea and hexamethylenetetramine are added to the sol of silicic acid and up to 70\% (w/w) of the exchanger. This mixture is dispersed into an organic medium, such as silicon oil, at high temperature. The spherical particles produced during dispersion must be purified from residue of the organic dispersion medium before their use. A composite dried absorber containing AMP prepared by this procedure ${ }^{56}$ contained $65 \%(\mathrm{w} / \mathrm{w})$ of the active component and had a sorption capacity of $0.22 \mathrm{mmole}$ Cs. $\mathrm{mL}^{-1}$. Although drying this absorber slightly decreased the ion-exchange kinetics, the sorption capacity of a packed bed in-

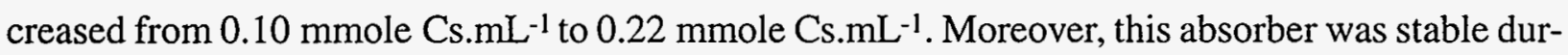
ing twenty sorption-elution cycles for 3 weeks of operation.

Krylov et al. ${ }^{57}$ produced a silica-gel matrix that contained higher loadings of the active component, which provided higher sorption capacity. Their laborious procedure included concentrating a dilute sol of silicic acid (prepared on cation exchangers) by evaporation to between $28 \%$ and $32 \%$ $(\mathrm{w} / \mathrm{w}) \mathrm{SiO}_{2}$. The finely divided active component of barium sulfate, activated by calcium, was added to this concentrated sol. The optimum ratio was $7 \mathrm{~g}$ of $\mathrm{SiO}_{2}$ to $100 \mathrm{~g}$ of $\mathrm{BaSO}_{4}$. Pellets produced by pressing the resulting paste through defined openings were dried at $100^{\circ} \mathrm{C}$. Suitable granules were obtained by sieving the crushed pellets. Elevating drying temperature above $100^{\circ} \mathrm{C}$ adversely affected the properties of this absorber material.

Another suitable inorganic binding material is alumina $\left(\mathrm{Al}_{2} \mathrm{O}_{3}\right)$. Dosch ${ }^{44}$ studied the properties of sodium titanate pellets produced by Norton Company (Akron, Ohio, USA). The pellets contained $10 \%$ to $30 \%$ of binder material and were dried using temperatures that ranged from ambient to $340^{\circ} \mathrm{C}$. Pellets with satisfactory strength and strontium sorption capacity were produced by calcining at $320^{\circ} \mathrm{C}$ for 1 hour from mixtures containing $70 \%$ sodium titanate and $30 \%$ alumina.

The strength of pellets prepared with calcium aluminate, ${ }^{44}$ another material used to prepare pellets of sodium titanate, was inferior to that of pellets containing alumina binder when both were dried at ambient temperature. Pellets with calcium aluminate binder were degraded by contact with caustic solutions.

2.3.2. Composite Absorbers with an Organic Binding Matrix. The development of organic macromolecular materials whose properties may be modified to meet various requirements also resulted in their being used to granulate or to modify many powdered materials. ${ }^{58-80}$ The classification of such materials is rather problematic because the patent literature contains broad classifications of polymers prepared and modified by many different procedures and because most of these polymers have rarely been used. 
White ${ }^{58}$ proposed a broad scale of hydrophylic gels for granulating finely divided ion-exchange materials. In his procedure, he usually used water-soluble material that had been gelled in an aqueous medium to a water-insoluble form. Such gelable material may be a natural substance (gelatin, cellulose) or may be synthetic gels formed by crosslinking polyacrylamide or polymethacrylamide. These synthetic gels may also be formed by polymerizing water-soluble vinyl monomers in an aqueous medium that contains a water-soluble crosslinking agent. Polyacrylamide gel was used by Shigetomi et al..$^{59}$ to prepare gel particles that contained various metal hydroxides, which were used as absorbers to collect uranium from sea water. A disadvantage of gel-based absorbers is their relatively high water content ( $70 \%$ to $90 \%$ ) and their poor stability in strong acid media.

Some of the procedures of agglomerating suspended particles patented by Rosenthal ${ }^{60}$ may also be used to prepare composite absorbers. The granulating agent in this case is a synthetic plastic dissolved in a liquid organic solvent. Plastics that serve as granulating agents include polyacrylic acids, polymethacrylates and their copolymers, polyvinyl acetates, cellulose derivatives, polystyrene, polyamides, and polycarbonates.

To improve the granular properties of powdered ion exchangers, polymers slightly soluble in water (such as polyvinyl alcohol) were used. Yoroda61 mixed an aqueous solution of polyvinyl alcohol with natural bentonite and dried and pulverized the resulting paste. A disadvantage of this process is the slow dissolution of the organic binding polymer, especially at elevated temperatures.

Hydrophobic binding agents can be used if they are added in an amount just sufficient to bind the particles together, but not enough to prevent contact between the inorganic material and the solution. Stejskal et al.62,63 used polyvinyl acetate, polystyrene, polyvinyl chloride, polymethyl methacrylate, and epoxy resin as binding materials. The organic polymer was dissolved in a suitable organic solvent and mixed with powdered sorbent to produce a paste that was dried, crushed, and sieved. Ammonium molybdophosphate and zinc hexacyanoferrate were granulated in this way. A similar procedure ${ }^{64}$ was also used to prepare granules of nickel hexacyanoferrate with polyvinyl chloride.

The preparation of composite ion exchangers composed of hydrated oxides of titanium, zirconium, or tin and a thermosetting resin (binding matrix) as an epoxy, unsaturated polyester, or polyurethane resin was described by Takeuchi et al.65 The resulting composite absorbers are suitable for separating many anions (especially phosphate ions) and cations. They can be regenerated and used over a long period of time. These absorbers are prepared by directly mixing the powdered dry metal oxide hydrate (or their mixtures) with liquid resin or with a solution of the resin in a suitable organic solvent. The mixed components are cured at room temperature or at elevated temperatures up to $90^{\circ} \mathrm{C}$. The cured material is then crushed and sieved.

The procedure used to prepare macroreticular spherical cellulose from viscose ${ }^{46}$ was also proposed for the preparation of composite absorbers. This procedure may be applied to inorganic ion 12 
exchangers that are sufficiently stable in an aqueous alkaline solution of technical viscose cellulose. Composite absorbers containing $\mathrm{PbS}$ and $\mathrm{SiO}_{2}$ were prepared by this method.

For supporting biomasses that contain the mycelia of micro-organisms (preparation of so-called "biosorbents") a polymerizable component from the group consisting of formaldehyde, resorcinol, urea, epoxide resin, acrylic resin, etc., was found to be suitable. ${ }^{66}$ The solid product is crushed and sieved. Such material has good sorption properties for uranium and heavy metals. A similar procedure for supporting biomasses of plant or algae material makes use of urea or urea with formaldehyde as the binder. 67 The crushed and sieved product polymerized at $100^{\circ} \mathrm{C}$ is suitable for separating uranium and heavy metals. An improved procedure ${ }^{68}$ for supporting the biomasses of mycelia fungi involves the dispersion of dry biomass in a nonpolar organic medium, agglomeration of the dispersed biomass with a polymerizing component, such as formaldehyde, formaldehyde-resorcinol, formaldehyde-urea, and a surface-active agent in a solvent that is immiscible with the dispersion medium. The polymerization reaction of the agglomerated mixture is initiated by adding a catalyst and heating the mixture to at least $70^{\circ} \mathrm{C}$.

Phenolic resin ${ }^{69}$ was used to prepare spherical particles of composite absorbers with metal hydroxides as the active components. Phenolic resin is first precondensed with an aldehyde compound in the presence of an acid catalyst. A metal salt or oxide is then incorporated into the reaction mixture. Salts of titanium, iron, aluminum, zirconium, tin, antimony, etc., may be used. A polycondensation reaction is completed while the resulting reaction mixture is suspended in a suitable medium, such as carbon tetrachloride, chloroform, or chlorobenzene at temperatures of $70^{\circ} \mathrm{C}$ to $150^{\circ} \mathrm{C}$. After the reaction is complete, the resulting absorber is removed from the reaction mixture and treated with an alkaline agent. Such absorbers can be used to purify various waste waters, including wastes from nuclear power plants.

Phenolsulfonic-formaldehyde resin was used by Narbutt et al. ${ }^{70}$ to prepare composite ion exchangers in the form of spherical beads. A flow diagram of the preparation is shown in Fig. $3{ }^{71}$ The polycondensation process also was operated in a fluid reactor on a pilot-plant scale. Composite absorbers containing the following active components have been prepared by this procedure: hexacyanoferrates of titanium(IV), ${ }^{72-75}$ zinc, $^{71,72,76}$ nickel, ${ }^{71,72,76}$ copper, ${ }^{71}$ and cobalt, ${ }^{72,75,77}$ as well as titanium phosphate, ${ }^{75}$ synthetic mordenite, ${ }^{72,75}$ and hydrated antimony pentoxide (polyantimonic acid). ${ }^{72,78}$ Phenolsulfonic-formaldehyde composite absorbers typically contain $15 \%$ to $35 \%(\mathrm{w} / \mathrm{w})$ of the active component in dried residue, ${ }^{71,75}$ with the exception of hydrated antimony pentoxide absorber, which contains $60 \%$ of the inorganic filler. ${ }^{72,78}$

The mechanical stability of the composite beads of $1 \mathrm{~mm}$ diameter was 25 to $30 \mathrm{~N} .{ }^{75} \mathrm{~A}$ review of potential applications of these absorbers in nuclear and radioanalytical chemistry was presented at the SIS '93 conference (Stará Lesna, Slovak Republic) and was submitted for publication. ${ }^{79}$ The phenolsulfonic-formaldehyde matrix is chemically stable in strongly acidic to slightly alkaline media, 


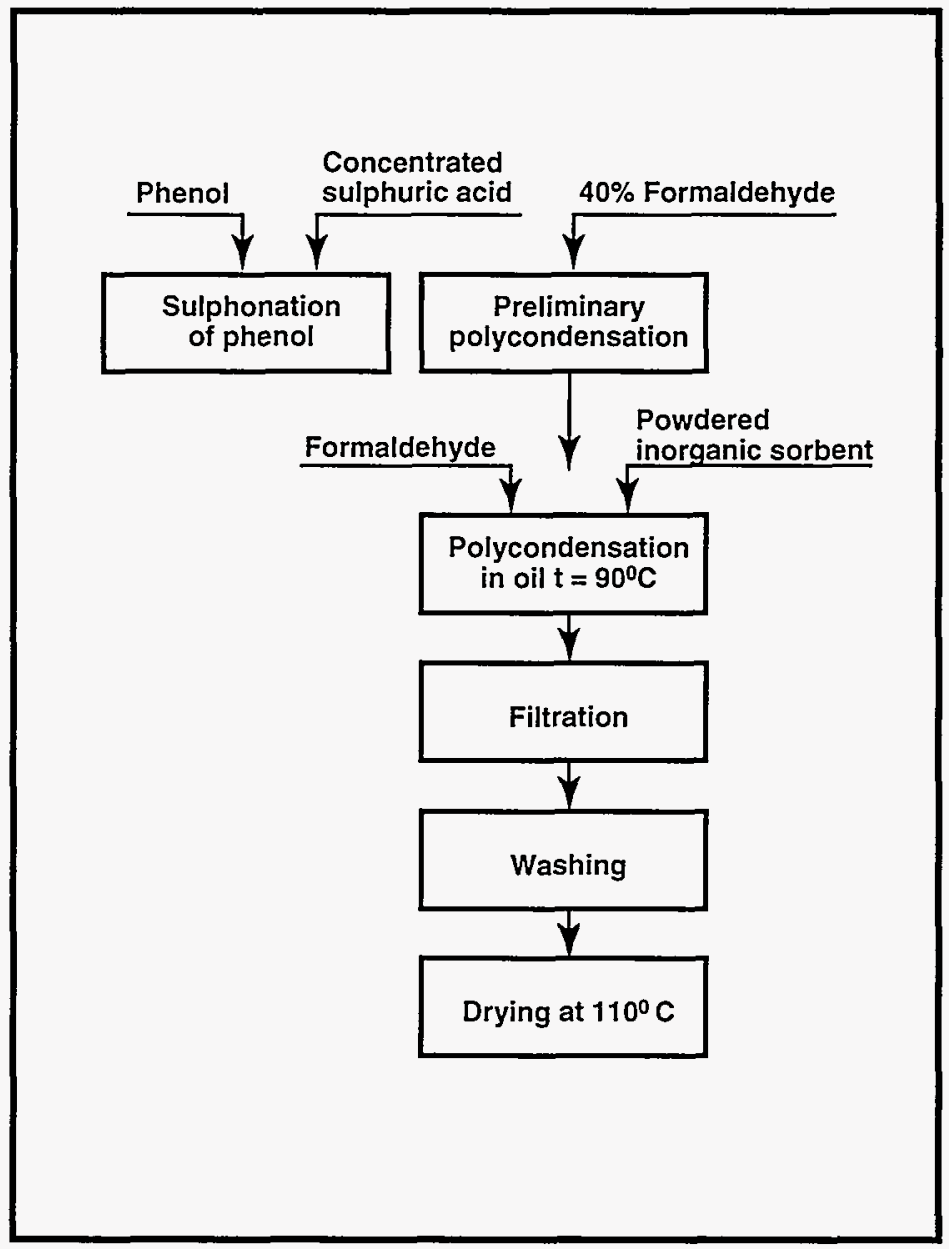

Fig. 3. Generic procedure for preparing spherical phenolsulfonic-formaldehyde composite beads. ${ }^{11}$

except for solutions containing oxidizing agents, such as 5 to $7 \mathrm{MHNO}_{3}$, in which the matrix slowly degrades. ${ }^{79}$ The phenolsulfonic-formaldehyde binder is not totally inert, for it behaves as a strong-acid cation exchanger. ${ }^{72}$

The described preparation procedure is unsuitable for active components that are unstable in sulfuric acid. Although these composite absorbers offer advantages for many potential nuclear applications, ${ }^{79}$ their main disadvantage is rather slow ion-exchange kinetics in moderate-to-high salt solutions. ${ }^{73,75,77}$

A sulfonated polystyrene-divinylbenzene polymer ${ }^{80}$ was used to prepare a composite absorber containing hydrated antimony pentoxide as the active component. The prepared absorber contained $\sim 40 \%$ (w/w) of inorganic filler and was synthesized in a block polymerization process from styrene, divinylbenzene, benzoyl peroxide, and powdered ( $<0.03 \mathrm{~mm}$ ) active component. The polymerization product was swollen in dioxane and sulfonated. The final product was washed with distilled water, then ground and sieved. This composite absorber was used for separating sodium 
from digested biological material in concentrated $\mathrm{HNO}_{3}$ solutions. However, the sorption capacity of this composite absorber was lower than the theoretical value. Attempts to obtain a composite absorber with a higher content of the active component were unsuccessful.

Modified polyacrylonitrile was proposed as a universal binding polymer for almost any inorganic ion exchanger (active component). ${ }^{4,5} \mathrm{~A}$ flowchart of the preparation of the composite ion exchangers containing modified PAN as the binding polymer is shown in Fig. 4.

This procedure can be modified or simplified in several ways. Initial components (or their solutions) for preparing the inorganic ion exchanger can in some cases be mixed directly with the solution of the binding polymer, instead of using the ready-made dried and powdered exchanger. The active component of the composite ion exchanger is then formed during (or after) the coagulation of the binding polymer. Another possibility is to mix one of the components of the inorganic ion exchanger with the solution of the binding polymer while the other component is dissolved in the coagulation bath.

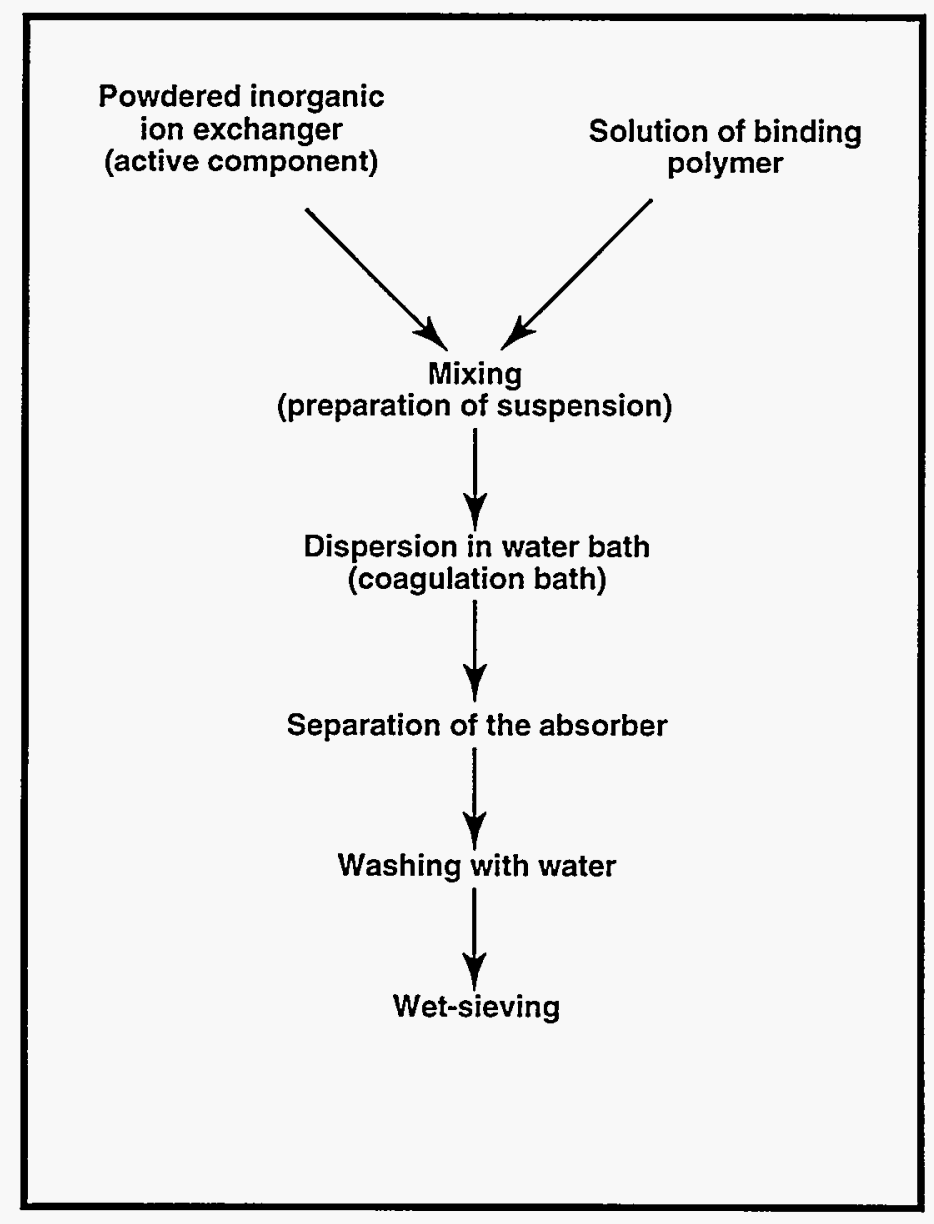

Fig. 4. Generic procedure for preparing composites of inorganic exchange materials using modified polyacrylonitrile (PAN) as the binder. 
These methods enable incorporation of very fine to colloidal particles of the active component in the binding polymer, which increases the capacity and improves the ion-exchange kinetics of the resulting absorber. The final product can be shaped as grains, beads, fibers, felt, fabric, membranes, or tubing. From an economics perspective, it is worth mentioning that even some industrial-grade PAN can be used to prepare these composite ion exchangers.

The use of PAN-based organic binding polymer has a number of advantages related to the relative ease with which its physicochemical properties (hydrophylicity, porosity, mechanical strength) are modified. These properties can be modified by the degree of polymer crosslinking, the use of suitable copolymers, or by the composition and temperature of the coagulation bath. Another advantage is the ability to prepare the composite ion exchangers directly in the aqueous solution, eliminating the possibility of introducing water-immiscible solvents and oils that would require subsequent removal by washing.

The ion-exchange kinetics of such composite ion exchangers is not influenced by the PAN binding polymer. The contents of the active component in the composite exchanger can be varied over a wide range ( $5 \%$ to $90 \%$ of the dry weight of the composite ion exchanger), depending on the intended application.

The PAN-binding polymer is stable in all aqueous solutions of common electrolytes, except for concentrated solutions of $\mathrm{ZnCl}_{2}, \mathrm{LiBr}, \mathrm{CaCl}_{2}$, and $\mathrm{NaSCN}$, which are known to dissolve polyacrylonitrile. However, this polymer dissolves in acids more concentrated than $8 \mathrm{M} \mathrm{HNO}_{3}, 5$ $\mathrm{M} \mathrm{H}_{3} \mathrm{PO}_{4}$, or $5 \mathrm{M} \mathrm{H}_{2} \mathrm{SO}_{4}$. It also hydrolyzes to gel after prolonged contact with acid or alkaline solutions.

The described method is suitable for most of the inorganic ion exchangers known. A list of composite ion exchangers already produced in our laboratory is shown in Table I. These composite absorbers have been developed and most have been tested for the selective separation and concentration of radionuclides from environmental samples, as well as removal from radioactive liquid wastes produced in the operation and decommissioning of nuclear power plants. 


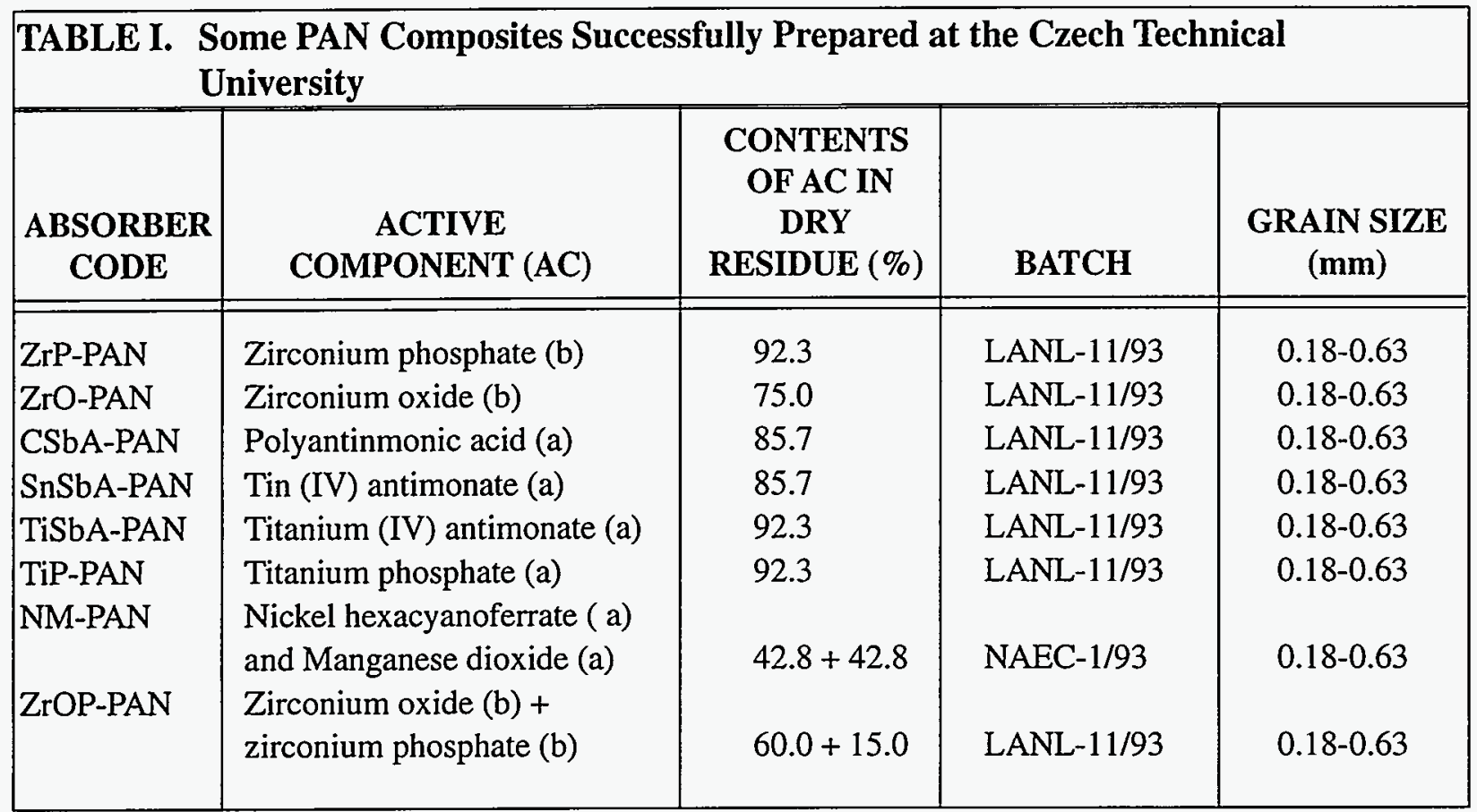

a - laboratory preparation

$\mathrm{b}$ - commercial product

An overview of some possible applications of PAN composites for treating radioactive liquid wastes was presented at the 1993 International Conference on Nuclear Waste Management and Environmental Remediation. ${ }^{6}$ A more detailed description of the properties of PAN-based composite absorbers containing ammonium molybdophosphate as the active component also has been published. ${ }^{81}$ The numerous non-nuclear-fuel-cycle applications of PAN-based composite absorbers include the determination of ${ }^{137} \mathrm{Cs}$ in fresh and sea water, digested biological materials, fresh milk, and urine, and ${ }^{60} \mathrm{Co}$ in drinking, fresh, and sea water. Applications also include the separation and concentration of cesium from other alkali metals, uranium from surface water, radium from drinking and fresh water, and saline solutions.

The described composite ion exchangers are not limited only to radiochemical applications; they also can be used in many other concentration and separation procedures. 


\section{COMPOSITE ABSORBERS PROVIDED FOR EVALUATION AT LANL}

All composite absorbers furnished to LANL were prepared according to the general procedure $^{5,6}$ from powdered (grain size $<0.1 \mathrm{~mm}$ ) active components of the respective inorganic ion exchangers. Two modifications of this method were used. The simplest and cheapest modification of the preparation procedure was applied to all composite absorbers in both shipments, except for $\mathrm{Ba}(\mathrm{Ca}) \mathrm{SO}_{4}$-PAN and AMP-PAN composite absorbers. We advise that composite absorbers prepared by this simple, cheap method should never be dried before use because of possible dramatic deterioration of their sorption properties. The likely adverse effects from drying are much less pronounced for absorbers prepared by the other procedure $\left(\mathrm{Ba}[\mathrm{Ca}] \mathrm{SO}_{4}-\mathrm{PAN}\right.$ and $A M P-P A N$, first shipment).

The active components used to prepare the composite absorbers were laboratory preparations synthesized according to published procedures, commercial preparations, or intermediate compounds from the pigment industry (see Tables II and III). The prepared composite absorbers were thoroughly washed with distilled water and wet-sieved after removing fines by decanting. For most test experiments, the fraction with a grain size of approximately 0.2 to $0.6 \mathrm{~mm}$ was selected. All absorbers were kept wet in polyethylene bottles before testing.

\subsection{First Shipment of Absorbers}

The first set of composite absorbers, sent to LANL at the beginning of February 1993, contained nine different composite absorbers that had previously been prepared and tested at CTU (Table II). The following active components were used for their preparation:

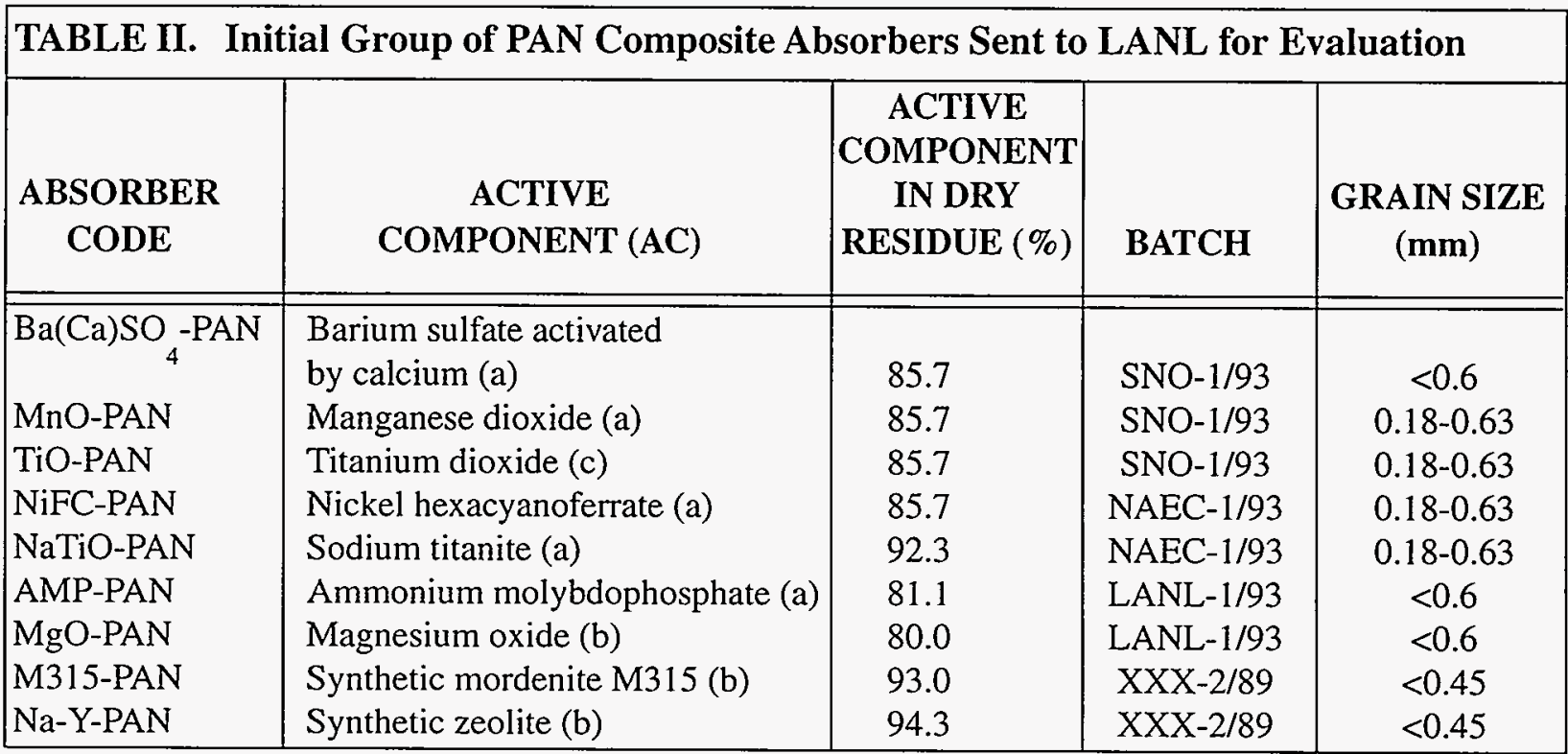

a - laboratory preparation

b - commercial product

c - intermediate from pigment industry 
Barium sulfate activated by calcium was precipitated, according to the procedure of Berák, 82 by adding one part of mixed $1 \mathrm{M} \mathrm{BaCl}_{2}+1 \mathrm{M} \mathrm{CaCl}_{2}$ solution (7:1) to two parts of $1 \mathrm{M} \mathrm{Na}_{2} \mathrm{SO}_{4}$. The resulting precipitate was filtered, and the filtration cake was first washed with a small volume of distilled water, and then dried, powdered, and sieved.

Manganese dioxide was prepared according to the reaction: ${ }^{83}$

$2 \mathrm{KMnO}_{4}+3 \mathrm{MnSO}_{4}+2 \mathrm{H}_{2} \mathrm{O} \rightarrow 5 \mathrm{MnO}_{2}+\mathrm{K}_{2} \mathrm{SO}_{4}+2 \mathrm{H}_{2} \mathrm{SO}_{4}$.

The solution of manganese sulfate $\left(0.5\right.$ mole. $\left.\mathrm{L}^{-1}\right)$ was stirred at $80^{\circ} \mathrm{C}$ to $90^{\circ} \mathrm{C}$ and the precipitate slowly formed by adding a stoichiometric amount of potassium permanganate solution ( 0.22 mole. $\left.\mathrm{L}^{-1}\right)$. After cooling and sedimentation, the precipitate was filtered and washed with distilled water until the filtrate $\mathrm{pH}$ was $>4$. Then the filtration cake was dried, powdered, and sieved.

Titanium dioxide was prepared from its water suspension produced as an industrial intermediate from the sulfate process for producing titanium pigments (Pŕerov Chemical Factory, Czech Republic). The suspension in water was filtered, washed with water, dried, powdered, and sieved.

Sodium titanate with the composition $\mathrm{Na}_{4.11} \mathrm{Ti}_{9} \mathrm{O}_{20.2} \cdot 13.6 \mathrm{H}_{2} \mathrm{O}^{84}$ was prepared from powdered titanium dioxide (see above). To the suspension of $100 \mathrm{~g}$ of $\mathrm{TiO}_{2}$ in $1,000 \mathrm{~mL}$ of $\mathrm{C}_{2} \mathrm{H}_{5} \mathrm{OH}$, a solution of $\mathrm{NaOH}$ in water $\left(160 \mathrm{~g} \mathrm{NaOH}+320 \mathrm{~mL} \mathrm{H}_{2} \mathrm{O}\right)$ was added and stirred. The mixture was heated under a reflux condenser with vigorous stirring for 3 hours. The product was washed, filtered, powdered, and sieved. 85

Nickel hexacyanoferrate with the composition $\mathrm{Ni}_{2}\left[\mathrm{Fe}(\mathrm{CN})_{6}\right] \cdot x \mathrm{H}_{2} \mathrm{O}$ was prepared by precipitation from solutions of $\mathrm{H}_{4}\left[\mathrm{Fe}(\mathrm{CN})_{6}\right]$ and $\mathrm{NiSO}_{4}$ in stoichiometric amounts. ${ }^{86}$ After settling, the precipitate was separated by filtration, and the filtration cake was dried (without washing), powdered, and sieved.

Ammonium molybdophosphate $\left(\mathrm{NH}_{4}\right)_{3} \mathrm{PO}_{4} \cdot 12 \mathrm{MoO}_{3} \cdot 3 \mathrm{H}_{2} \mathrm{O}$ was the powdered commercial product supplied by Lachema, Brno (Czech Republic).

Magnesium oxide, grade BPC 68, was the commercial powdered product supplied by Lachema, Brno (Czech Republic) and was not treated or modified before use.

Synthetic mordenite M315 was the powdered commercial product prepared by VÚRUP, Bratislava (Slovak Republic) and supplied in the $\mathrm{Na}^{+}$cycle. Its molar ratio of $\mathrm{SiO}_{2}: \mathrm{Al}_{2} \mathrm{O}_{3}$ was approximately 12.8 .

Synthetic zeolite, NaY (Faujasit) was another powdered commercial product prepared by VÚRUP. Its molar ratio of $\mathrm{SiO}_{2}: \mathrm{Al}_{2} \mathrm{O}_{3}$ was approximately 5.7 .

\subsection{Second Shipment of Absorbers}

Some of the composite absorbers from the second set were prepared in response to a specific request from S. F. Marsh, then of LANL. These composite absorbers were prepared from antimonatebased active components and have been reported to exhibit high selectivity for $\mathrm{Pu}^{4+}$ and $\mathrm{Am}^{3+}$ ions 
from acid solution. ${ }^{87}$ In addition to antimonate-based composite absorbers, a few samples of composite absorbers containing other promising inorganic ion exchangers as their active components ${ }^{10}$ were shipped (e.g., zirconium phosphate, titanium phosphate, and zirconium oxide).

Subsequently, two types of "mixed" composite absorbers were prepared for testing. These absorbers contained mixtures of $\mathrm{NiFC}+\mathrm{MnO}$ or $\mathrm{ZrP}+\mathrm{ZrO}$ as the active components. These composite absorbers should allow a broader range of radionuclides to be simultaneously separated. An overview of the prepared composite absorbers is given in Table III. These mixed composite absorbers are entirely new and have not yet been tested. The following active components were used for their preparation:

\begin{tabular}{|l|l|}
\hline TABLE III. & $\begin{array}{l}\text { Recently Prepared PAN Composite Absorbers, Including } \\
\text { Some Not Yet Tested }\end{array}$ \\
\hline CODE & ACTIVE COMPONENT \\
\hline AMP-PAN & Ammonium molybdophosphate \\
NiFC-PAN & Potassium-nickel hexacyanoferrate \\
CoFC-PAN & Potassium-cobalt hexacyanoferrate \\
ZrP-PAN & Zirconium phosphate \\
TiP-PAN & Titanium phosphate \\
MnO-PAN & Manganese dioxide \\
TiO-PAN & Titanium oxide \\
ZrO-PAN & Zirconium oxide \\
MgO-PAN & Magnesium oxide \\
NM-PAN & Manganese dioxide and nickel hexacyanoferrate \\
ZrOP-PAN & Zirconium oxide and zirconium phosphate \\
NaTiO-PAN & Sodium titanate \\
CSbA-PAN & Crystalline antimonic acid \\
SnSbA-PAN & Tin (IV) antimonate \\
TiSbA-PAN & Titanium (IV) antimonate \\
Ba [Ca] SO -PAN & Barium sulfate activated by calcium \\
CuS-PAN & Copper sulfide \\
NaY-PAN & Synthetic zeolite NaY \\
M315-PAN & Synthetic mordenite M315 \\
CLIN-PAN & Natural clinoptilolite \\
\hline
\end{tabular}


Zirconium phosphate (acid form, dried), grade SCP 163, was a commercial powdered product supplied by MEL Chemicals, Manchester (U.K.) and was not treated or modified before using.

Zirconium oxide, grade X20632/03, also was a commercial powdered product supplied by MEL Chemicals, Manchester (U.K.) and was not treated or modified before using.

Crystalline antimonic(V) acid (polyantimonic acid) was prepared in our laboratory by hydrolysis of antimony pentachloride according to the usual procedure. 87,88

Tin(IV) antimonate was prepared according to a published procedure. ${ }^{87,89}$ Solutions of 4 $\mathrm{M} \mathrm{SbCl}_{5}$ and $4 \mathrm{M} \mathrm{SnCl}_{4}$ were mixed at $60^{\circ} \mathrm{C}$ (molar ratio $\mathrm{Sn}: \mathrm{Sb} \approx 0.5$ ), and this mixture was added to a volume of distilled water 25 times greater than the original solution, at $60^{\circ} \mathrm{C}$, to form a precipitate.

Titanium(IV) antimonate was prepared according to a published procedure. 87,90 Solutions of $4 \mathrm{M} \mathrm{TiCl}_{4}$ and $4 \mathrm{M} \mathrm{SbCl}_{5}$ mixed at $60^{\circ} \mathrm{C}$ (molar ratio Ti:Sb $=1.5$ ), and this mixture was added to a volume of distilled water 25 times greater than the original solution, at $60^{\circ} \mathrm{C}$, to form a precipitate.

Titanium phosphate was prepared at our laboratory by directly precipitating $15 \% \mathrm{TiCl}_{4}$ and adding it to a $70 \%$ excess of $4.8 \mathrm{M} \mathrm{H}_{3} \mathrm{PO}_{4}$. Once the $\mathrm{TiCl}_{4}$ solution was added to the phosphoric acid, water also was added and carefully mixed. The titanium phosphate precipitate was filtered and washed until it was free of chloride. ${ }^{91}$

For the preparation of composite absorbers that contained mixtures of the active components nickel hexacyanoferrate + manganese dioxide or zirconium oxide + zirconium phosphate, the individual active components described in this and preceding chapters were used. 


\section{APPLICATIONS OF COMPOSITE ABSORBERS}

\subsection{LANL Absorber Studies for Hanford High-Level Waste}

Los Alamos National Laboratory is screening many absorbers that may be useful for treating high-level waste stored in underground tanks at the Hanford Reservation, near Richland, Washington. During their tests with the CTU-prepared PAN composites, the LANL investigators chose to air-dry the PAN composites to constant weight at room temperature to maintain consistency with the other absorbers tested in their studies.92-95 Because the CTU-prepared composite absorbers were air-dried before these tests, rather than left wet as we had requested, their measured $\mathrm{Kd}$ values should be considered minimum values that might have been higher in the absence of air-drying.

The LANL researchers measured the distribution of 14 elements onto the first batch of PANcomposite absorbers from three simulant solutions that represented acid-dissolved sludge, acidified supernate, and alkaline supernate for Hanford HLW Tank 102-SY.92 These same researchers later measured the distribution of 15 elements onto both batches of PAN-composite absorbers from simulated Hanford double-shell slurry feed..$^{93}$

Recently, the LANL investigators measured the distribution of 12 elements onto both batches of PAN-composite absorbers from simulated Hanford neutralized current acid waste. ${ }^{94}$ In addition, several PAN-composite absorbers were included in a study of the effects of aqueous-soluble organic compounds on the sorption of cesium, strontium, and technetium on 18 selected absorbers. ${ }^{95}$

\subsection{Other Applications of PAN-Composite Absorbers}

We recently published a discussion of inorganic-organic composite absorbers with polyacrylonitrile binding matrix that cites successful applications of these materials. ${ }^{96}$ These recent applications include the determination of radionuclides $\left({ }^{137} \mathrm{Cs},{ }^{60} \mathrm{Co}, \mathrm{U}, \mathrm{Ra}\right)$ in the environment, treatment of various industrial and/or radioactive waste solutions, and the removal of natural and/or artificial radionuclides and heavy or toxic metals from underground water plumes. 96 


\section{ACKNOWLEDGMENTS}

The preparation of this report was supported by the U. S. Department of Energy. S. Fredric Marsh, currently employed by Sandia National Laboratories, NM, established the contract with the Czech Technical University during his previous employment by Los Alamos National Laboratory and also helped prepare this document for publication. 


\section{REFERENCES}

1. ŠEBESTA F., MOTL A., JOHN J.: Composite Ion-Exchangers, Their Development and Use. Workshop '92, Part B, Sect. 1, pp. 25-26, CTU Prague, 1992.

2. ŠEBESTA F., JOHN J., MOTL A., STEINEROVÁ J.: Development and Testing of Composite Ion-Exchangers, Workshop '93, Part C, Sect. 12, pp. 75-76, CTU Prague, 1993.

3. ŠEBESTA F., JOHN J., MOTL A., STEINEROVÁ J.: Development and Testing of Composite Ion-Exchangers, Workshop '94, Part A, Sect. 2, pp. 67-68, CTU Prague, 1994.

4. STOY V., ŠEBESTA F., JIRÁSEK V., STOY A.: Selective Absorber for Radium and the Procedure for Its Production. Czech Patent A.O. 181605, 1980 (in Czech).

5. ŠEBESTA F.: Exchanger Composed from an Active Component and a Binding Organic Matrix and the Way of Its Production. Czech Patent A.O.273 369, 1992 (in Czech).

6. ŠEBESTA F., MOTL A., JOHN J., PRǍZSKÝY M., BINKA J: Composite Ion-Exchangers and Their Possible Use in Treatment of Low/Intermediate Level Liquid Radioactive Wastes. In: Proc. 1993 Int. Conf. Nucl. Wastes Management and Environmental Remediation, September 5-11, 1993, Prague; Vol. 3, pp. 871-878, ASME, New York, 1993.

7. ŠEBESTA F., JOHN J., MOTL A.: Verification of Technology of Decreasing the Long Term Fuel Storage Pond Water Activity at NPP A-1. Faculty of Nuclear Sciences and Physical Engineering, CTU Prague 1992, 43 pp. (in Czech).

8. ŠEBESTA F., PETR J., HLADKÝ E., BRZOBOHATÝ J.: Proposal to a Tender for Technology of Lowering the Activity of Water from the Long Term Fuel Storage Pond at NPP A-1. Faculty of Nuclear Sciences and Physical Engineering, CTU Prague 1993, 23 pp. (in Czech).

9. Use of Inorganic Sorbents for Treatment of Liquid Radioactive Waste and Backfill of Underground Repositories. IAEA-TECDOC-675, CONF-9111297, November 4-8, 1991) IAEA Vienna, 1992, $189 \mathrm{pp}$.

10. HOOPER E.W., PHILLIPS B.A., DAGNALL S.P., MONCKTON N.P.: An Assessment of the Application of Inorganic Ion Exchangers to the Treatment of Intermediate Level Wastes. Report AERE-R 11088, 1984, 121 pp.

11. VESELÝ V., PEKÁREK V.: Synthetic Inorganic Ion Exchangers I. Hydrous Oxides and Acidic Salts of Multivalent Metals. Talanta, 19, 1972, pp. 219-262

12. PEKÁREK V., VESELÝ V.: Synthetic Inorganic Ion Exchangers II. Salts of Heteropolyacids, Insoluble Ferrocyanides, Synthetic Aluminosilicates, and Miscellaneous Exchangers. Talanta, 19, 1972, pp. 1245-1283.

13. JACOBI D.: Caesium Sorption by Inorganic Exchangers. DOE Report No.DOE/ HMIP/RR/92/011, Imperial College, London, UK, 1992, 145 pp.

14. Société des Techniques en Milieu Ionisant (STMI-RAN). Z.A.C. de Courcelle-1, route de la Noue 91196 GIF-SUR-YVETTE, France. 
15. PROUT W.E., RUSSELL E.R., GROH H.J.: Ion Exchange Absorption of Cesium by Potassium Hexacyanocobalt(II) Ferrate(II). J. Inorg. Nucl. Chem., 27, 1965, pp. 473-479.

16. LEHTO J., HARJULA R., TUSA E., PAAVOLA A.: Separation of Cesium from Nuclear Evaporator Concentrates with a Hexacyanoferrate Ion Exchanger. In: Proc. 1993 Int. Con. Nucl. Wastes Management and Environmental Remediation, September 5-11, 1993, Prague; Vol. 3, pp. 763-767, ASME, New York, 1993.

17. SMIT J. van R: Ion Exchange on Ammonium Molybdatophosphate III. Preparation Properties of Coarse Ammonium Heteropolyacids Salts. J. Inorg. Nucl. Chem., 27, 1965, pp. 227-232.

18. BERÁK L.: Procedure for Decontamination of Water Contaminated by Radium and Strontium-90. Czech Patent 102881, 1961 (in Czech).

19. FEDOROFF M., LOOS-NESKOVIC C.: French Patent 84-12139, 1984

20. LOOS-NESKOVIC C., ABOUSAHL S., FEDOROFF M.: Column-Usable Inorganic Fixator Preparation by Localized Growth on a Solid Alkaline Ferrocyanide, J. Mater. Sci. 25, 1990, pp. 677-682.

21. BERÁK L: Procedure for Decontamination of Water Contaminated by Radium and Radiostrontium with Metastable Crystals of Barium Sulphate with Artificially Introduced Defects of Calcium. Czech Patent 110625, 1961 (in Czech).

22. BERÁK L., MÜNICH J: Barium Sulfate Activated for Sorption of Strontium by Heat Treatment with Calcium Sulfate. Coll. Czech. Chem. Commun., 30, 1965, pp. 881-901.

23. SASAKI T., KOMATSU Y., FUJIKI Y.: Sorption Properties and Some Separations of Divalent Transition Metal Ions on Crystalline Hydrous Titanium Dioxide Fibers. Separ. Sci. Techn., 18, 1983, pp. 49-58.

24. CLEARFIELD A., LEHTO J.: Preparation, Structure and Ion-Exchange Properties of $\mathrm{Na}_{4} \mathrm{Ti}_{9} \mathrm{O}_{20} \cdot \mathrm{xH}_{2} \mathrm{O}$. J. Solid State Chem., 73, 1988, p. 98.

25. BERÁKL., UHER E., MARHOL M.: Sorbents for the Purification of Low- and Medium-Level Radioactive Waters. Atomic Energy Review, 13, 1975, pp. 325-366.

26. SHARYGIN M., POSPELOV A.A., CHUKHLANTSEV V.G.: Modification of Precipitates of Zirconyl Phosphate by Freezing. Radiokhimiya, 7, 1965, pp. 744-747 (in Russian).

27. SHARYGIN M., POSPELOV A.A., CHUKHLANTSEV V.G.: Production of Granular Zirconyl Phosphate by Freezing and Its Ion-Exchange Properties. Radiokhimiya, 11, 1969, pp. 568-573 (in Russian).

28. EGOROVA N.V., KRYLOV V.N., PITALEV V.G., STEPANOV A.V.: Inorganic Absorbers in Radiochemical Analysis of Sea Water. Radiokhimiya, 5, 1978, pp. 737-741 (in Russian).

29. BARAN V., CALETKA R., TYMPL M., URBÁNEK V.: Application of the Sol-Gel Method for the Preparation of some Inorganic Ion-Exchangers in Spherical Form. J.Radioanal.Chem., 24, 1975, pp. 353-359. 
30. CALETKA R., TYMPL M.: Uptake of Inorganic Acids on Hydrogels of Tetravalent Hydroxides and Its Application for the Preparation of Some Inorganic Sorbents. J. Radioanal. Chem., 30, 1976, pp. 155-172.

31. MELICHAR F., TYMPL M.: Inorganic Absorbers Prepared by Sol-Gel Method. Nukleon, 1986, pp. 13-16 (in Czech).

32. KONEČNÝ C., CALETKA R.: Adsorption Properties of Insoluble Hexacyanoferrates(II) Supported on Silica Gel. J.Radioanal. Chem., 14, 1973, pp. 255-266.

33. CALETKA R., KONEČNÝ C.: Adsorption Properties of Phosphoantimonic Acid Supported on Silica Gel. Radiochem. Radioanal. Lett., 9, 1972, pp. 285-293.

34. CALETKA R., KONEČNY C., SIMKOVÁ M.: Removal of Sodium from Mineral Acid, Solution by Adsorption on Modified Polyantimonic(V) Acid Ion-Exchanger. J. Radioanal. Chem., 10, 1972, pp. 5-15.

35. CALETKA R., KONEČNÝ C.: Adsorption Properties of Ammonium Molybdophosphate Supported in Pores of Silica Gel. Radiochem. Radioanal. Lett., 12, 1972, pp. 325-329.

36. TERADA K., HAYKAWA H., SAWADA K., KIBA T.: Silica Gel as a Support for Inorganic Ion-Exchangers for the Determination of Caesium-137 in Natural Waters. Talanta, 17, 1970, pp. 955-963.

37. GANZERLI M.T.V., STELLA R., MAGGI L., CICERI G.: Copper Hexacyanofer-rate(II) and (III) as Trace Cesium Absorbers from Natural Waters. J. Radioanal. Nucl. Chem., Articles, 114, 1987, pp. 105-112.

38. WILDING M.W.: Cesium Removal from Acidic Radioactive Waste Solutions. USAEC report IDO-14544, 1961.

39. BILEWICZ A., SCHENKER E.: Adsorption of Radionuclides on Oxide Sorbents and Impregnated Porous Membranes under High Temperature Conditions. IAEA-TECDOC-675, IAEA Vienna, 1992, pp. 173-187.

40. WATARI K., IMAI K., IZAWA M.: Isolation of ${ }^{137} \mathrm{Cs}$ with Copper Ferrocyanide Anion Exchange Resin. J. Nucl. Sci. Techn. 4, 1967, pp. 190-194.

41. WATARI K., IMAI K., OHMOMO Y., MURAMATU Y., NISHIMURA Y.,IZAWA M., BACILES L.R.: Simultaneous Adsorption of Cs-137 and I-131 from Water and Milk on Metal Ferrocyanide-Anion Exchange Resin, J. Nucl. Sci. Techn. 25, 1988, pp. 495-499.

42. LEHTO J., HARJULA R., TUSA E., PAAVOLA A.: Industrial Scale Removal of Cesium with Hexacyanoferrate Exchanger - Process Development. Waste Management '93, (Tucson, Arizona, February 28-March 4, 1993).

43. CUNHA I.I.L., SAKAI L.: Determination of Cesium-137 in Water by Ion Exchange. J. Radioanal. Nucl. Chem., 131, 1989, pp. 105-109. 
44. DOSCH R.G.: Final Report on the Application of Titanates, Niobates and Tantalates to Neutralized Defense Waste Decontamination - Materials, Properties, Physical Forms and Degeneration Techniques. Sandia National Laboratories, SAND 80-1212, 1980, 67 pp.

45. NAKAOKA A., YOKOYAMA H., FUKUSHIMA M., TAKAGI S.: Rapid Determination Method of Radiocesium in Sea Water by Selective Resin. J. Radioanal. Chem., 56, 1980, pp. 13-24.

46. LENFELD J. et al.: Composite Absorber and the Way of Production of this Absorber. Czech Patent A.O. 228489, 1986 (in Czech).

47. PROCHÁZKA H. et al.: Application of Special Absorbers for Treatment of Radioactive Wastes. Report of Research Institute of Veterinary Medicine, Brno, 1987, 23 pp. (in Czech).

48. KRISHNASWAMI S., LAB D., SOMAYAJULU B.L.K., DIXON F.S., STONECIPHER S.A., CRAIG H.: Silicon, Radium, Thorium and Lead in Sea Water. In Situ Extraction by Synthetic Fiber. Earth Planet. Sci. Lett., 16, 1972, pp. 84-90.

49. MOORE W.S., REID D.F.: Extraction of Radium from Natural Waters Using Manganese Impregnated Acrylic Fibers, J. Geophys. Res. 78, 1973, pp. 8880-8886.

50. MOORE W.S., COOK L.M.: Radium Removal from Drinking Water, Nature, 253, 1975, pp. 262-263.

51. MOOREW.S.: Sampling ${ }^{228}$ Ra in the Deep Ocean. Deep-Sea Research, 23, 1976, pp. 647-651.

52. HIGUCHI H. et al.: Material for Collecting Radionuclides and Heavy Metals. U.S. Patent $4720422,1988$.

53. ROGINSKII S.Z.: Production of Concentrates of Radioactive Isotopes of Caesium on Ferrocyanides of Heavy Metals from Solutions with High Concentration of Other Salts. Radiokhimiya, 2, 1960, pp. 438-445 (in Russian).

54. PEETERS K.J.A., VAN DE VOORDE N.L.C.: Decontamination Process for Radio-active Liquids. U.S. Patent 3896045, 1975.

55. TYMPL M., BARAN V., DOLEŽAL J., KINZELOVÁ J., KOUŘÍM V., STEJSKAL J., SEPS V., URBÁNEK V.: Procedure for Production of Beads. Czech Patent A.O. 158508, 1975 (in Czech).

56. DOLEŽAL J., STEJSKAL J., TYMPL M., KOUŘÍM V.: Improved Inorganic Ion-Exchangers II. Ammonium Molybdophosphate - Silica Gel System. J. Radioanal. Chem., 21, 1974, pp. 381-387.

57. KRYLOV B.N. et al.: Inorganic Absorbers in Radiometric Analysis of Sea Water. Radiokhimiya, 75, 1973, pp. 662-665 (in Russian).

58. WHITE M.L.: Novel Gel Compositions and Methods for Preparation thereof. U.S. Patent 3284238, 1966. 
59. SHIGETOMI Y., KOJIMA T., SHINAGAWA M.: Basic Study on Uranium Extraction from Sea Water, (II). Extraction of Uranium(VI) by Polyacrylamide Gel Containing Various Metal Hydroxides. J. Nucl. Sci. Technol., 14, 1977, pp. 811-815.

60. ROSENTHAL C.: Method for Agglomerating Suspended Particles. U.S. Patent 3577489, 1971.

61. YORODA T.: Ion-Exchange Materials. Japanese Patent 20828, 1963.

62. STEJSKAL J. et al.: Improved Inorganic Ion-Exchangers. I. System with Organic Polymers as Binding Materials. J. Radioanal. Chem., 21, 1974, pp. 371-379.

63. SOUKUP J. et al.: Procedure for Modification of Inorganic Absorbers. Czech Patent A.O. 140896, 1971 (in Czech).

64. BELAYEVA S.Y., SAKHAROVA I.N., IOVCHEV R.I.: Procedure for Preparation of Ferrocyanide-based Absorber in Polymeric Matrix.. SU Patent 1012969, 1983 (in Russian).

65. TAKEUCHI T., SOKUKAWA M., KIMOTO R.: Ion Exchanger of Hydrated Oxide of Ti, Zr, or Sn and Cured Polyester, and Exchange Method. U.S. Patent 4362626, 1982.

66. NĚMEC P. et al.: Process of Treating Mycelia of Fungi for Retention of Metals. U.S. Patent $4021368,1977$.

67. ̌EZÁC J. et al.: Procedure for Production of Biosorbent. Czech Patent A.O. 201705, 1983 (in Czech).

68. VOTÁPEK V. et al.: Method of Treating a Biomass. U.S. Patent 4067821, 1978.

69. ECHIGO Y., SUEMATSU Y., ISHIKURA T.: Spherical Ion Exchange Resin Having Matrix-Bound Metal Hydroxide, Method for Producing the same and Method for Adsorption Treatment Using the same. U.S. Patent 4576969, 1986.

70. NARBUTT J., BARTOŠ B., BILEWICZ A., SZEGLOWSKI Z.: Method of Obtaining Composite Ion Exchangers. U.S. Patent 4755322, 1988.

71. BARTOŠ B., LOOS-NESKOVIC C.: Use of Composite Sorbents Containing Insoluble Hexacyanoferrates II for Radiocesium Removal from Reactor Waste Solutions. In: Ion Exchange Processes: Advances and Applications, (A. Dyer, M.J. Hudson, P.A. Williams, Eds), Proc. Inter. Conf. Ion-Ex '93, Wrexham, UK, April 4-7, 1993, Royal Soc. Chem., Cambridge, 1993, pp. 63-72.

72. NARBUTT J., BILEWICZ A., BARTOŠ B.: Composite Ion Exchangers Selective to Cations of Alkali Metals, Chem. Anal. (Warsaw), 33, 1988, pp. 399-410.

73. NARBUTT J., BILEWICZ A., BARTOŠ B., SIWINSKI J.: Composite Ion Exchangers for Radiocesium Removal from Nuclear Reactor Wastes. In: Proc. Management of Low and Intermediate Level Radioactive Wastes, IAEA-SM-303/152P IAEA, Vienna, 1989, Vol 2, pp. 266-268. 
74. NARBUTT J., BILEWICZ A., BARTOS B., SIWINSKI J.: Application of New Composite Ion Exchangers for the Removal of Radionuclides from the Primary Coolant of Water Reactors, Part 1, IAEA-TECDOC-667, IAEA, Vienna, 1992, Vol. 1, pp. 102-105.

75. NARBUTT J., BILEWICZ A., BARTOS B., SIWINSKI J.: Application of New Composite Ion Exchangers for the Removal of Radionuclides from the Primary Coolant of Water Reactors, Part 2, IAEA-TECDOC-667, IAEA, Vienna, 1992, Vol. 1, pp. 105-107.

76. LOOS-NESKOVIC C., BARTOS B., HUSSONNOIS M., CONSTANTINESCU O.: Fr and Ra Fixation on Some Inorganic Sorbents or Mixed Composite Ion Exchangers, J. Radioanal. Nucl. Chem., Lett. 155, 1991, pp. 243-251.

77. NARBUTT J., TALEB H., BARTOS B.: Studies on Radiocesium Removal from Aqueous Solutions Containing Chelating Agents and Ammonia, Using Composite Ion Exchangers. Reprint from the Annual Report of the Inst. of Nucl. Chem. Techn., Warsaw (Poland) 1992.

78. BILEWICZ A., BARTOŠ B., NARBUTT J. POLKOWSKA-MOTRENKO H.: Composite Ion Exchangers for Removal of Sodium-24 in Neutron Activation Analysis of Biological Materials, Anal. Chem., 59, 1987, pp. 1737-1738.

79. NARBUTT J., BILEWICZA., BARTOŠ B.: Composite Ion Exchangers - Prospective Nuclear Applications. Submitted to J. Radioanal. Nucl. Chem.

80. POLKOWSKA-MOTRENKO H., ZMIJEWSKA W., BARTOS B., BILEWICZ A., NARBUTT J.: Composite Ion Exchangers for Removal of Sodium-24 from Mineralizates of Biological Materials in Neutron Activation Analysis. J.Radioanal. Nucl. Chem., Letters, 164, 1992, pp. 115-122.

81. ŠEBESTA F., ŠTEFULA V.: Composite Ion-Exchanger with Ammonium Molybdophosphate and Its Properties. J. Radioanal. Nucl. Chem., 140, 1990, pp. 15-21.

82. BERÁK L.: Activated Barium Sulphate as a Sorbent of Small Quantities of Strontium. Coll. Czech. Chem. Comm., 30, 1965, pp. 1490-1504.

83. BIGLIOCCA C., GIRARDI F., PAULY J., SABBIONI E.: Radiochemical Separations by Adsorption on Manganese Dioxide. Anal. Chem., 39, 1967, pp. 1634-1639.

84. ŠEBESTA F., MOTL A.: Czech Technical University, Prague, Unpublished results.

85. HEINONEN O.J., LEHTO J., MIETTINEN J.: Sorption of Strontium(II) and Radio Strontium Ions on Sodium Titanate. Radio-chim. Acta, 28, 1981, pp. 93-96

86. ŠEBESTA F., ŠTEFULA V.: Czech Technical University, Prague, Unpublished results.

87. TSUJI M. et al.: Synthetic Inorganic Ion Exchangers Showing High Selectivity towards $5 f$ Elements. Radiochim. Acta, 60, 1993, pp. 93-98.

88. ABE M., ITO T.: Synthetic Inorganic Ion Exchange Materials. X. Preparation and Properties of So-Called Antimonic(V) Acid. Bull. Chem. Soc. Japan, 41, 1968, pp. 333-342. 
89. ABE M., HAYASHI K.: Synthetic Inorganic Ion-Exchange Materials XXXIII. Selectivities of Alkali Metal Ions on Tin(IV) Antimonate Cation-Exchanger Prepared at Different Conditions. Solvent Extr. ion-Exch., 1, 1983, pp. 97-112.

90. ABE M. et al.: Synthetic Inorganic Ion-Exchange Materials XXXIX. Synthesis of Titanium(IV) Antimonates and Their Ion-Exchange Properties for Alkali and Alkaline Earth Metal Ions. Solvent Extr. ion-Exch., 3, 1985, pp. 149-172.

91. PHILIPS B.A. et al.: Study of the Behavior of Inorganic Ion Exchangers in the Treatment of Medium Active Effluents. Part I. Report AERE-G 2872, 1984, 68 pp.

92. MARSH S.F., SVITRA Z.V., BOWEN S.M. : Distributions of 14 Elements on 63 Absorbers from Three Simulant Solutions (Acid-Dissolved Sludge, Acidified Supernate, and Alkaline Supernate) for Hanford HLW Tank 102-SY. Los Alamos National Laboratory report LA-12654, Rev., August 1994, 102 pp.

93. MARSH S.F., SVITRA Z.V., BOWEN S.M. : Distributions of 15 Elements on 58 Absorbers from Simulated Hanford Double-Shell Slurry Feed (DSSF). Los Alamos National Laboratory report LA-12863, November 1994.

94. SVITRA Z.V., MARSH S.F., BOWEN S.M. : Distributions of 12 Elements on 60 Absorbers from Simulated Hanford Neutralized Current Acid Waste. Los Alamos National Laboratory report LA-12889, December 1994.

95. MARSH S.F., SVITRA Z.V., BOWEN S.M. : Effects of Aqueous-Soluble Organic Compounds on the Removal of Selected Radionuclides from High-Level Waste. Part I: Distributions of Cs, Sr, and Tc onto 18 Absorbers from an Irradiated Simulant for Hanford Tank 101-SY. Los Alamos National Laboratory report LA-12862, January 1995.

96. ŠEBESTA F., JOHN J., MOTL A. : Separation and Concentration of Contaminants Using Inorganic-Organic Composite Absorbers, BUDAPEST '94 Second International Symposium and Exhibition on Environmental Contamination in Central and Eastern Europe, September 20-23, 1994, Budapest, Hungary, in press. 